\title{
RESERVOIR CHARACTERISATION AND MODELLING IN A FRACTURED UPPER CAMBRIAN QUARTZITE RESERVOIR, ALGERIA
}

\author{
K.A. FOXFORD ${ }^{1}$, J.C. GUTMANIS ${ }^{1}$, M.M. BOWLER ${ }^{2}$, A. LAHMAR ${ }^{3}$, J.A. LORSONG ${ }^{4}$. \\ ${ }^{1}$ GeoScience Limited, Falmouth Business Park, Bickland Water Road, Falmouth, Cornwall, TR11 4SZ \\ ${ }^{2}$ BP Exploration Operating Co Ltd, Algeria Oil Business Unit, Chertsey Road, Sunbury on Thames, \\ Middlesex, TW16 7LN \\ ${ }^{3}$ Sonatrach, Division P.E.D., 8 Chemin de Réservoir, Hydra, Algiers, Algeria \\ ${ }^{4}$ BP Exploration Operating Co Ltd, Upstream Technology Group, Burnside Road, Farburn Industrial \\ Estate, Dyce, Aberdeen, AB21 7PB.
}

\section{INTRODUCTION}

This presentation describes reservoir characterisation carried out on an Upper Cambrian fractured quartzite reservoir at Rhourde El Baguel field in eastern Algeria. The field, which started production in 1963, was taken over by Sonarco in 1996 who initiated infill drilling and a miscible gas enhanced oil recovery project. Subsequently the field has come under the ownership of BP / Sonarco.

The highly heterogeneous geology and flow properties of the reservoir host rock were expected to have a significant impact on the performance and success of the miscible gas flood. A robust description of the fracture system was essential to reduce uncertainties associated with flood efficiency and recovery. In addition, primary depletion of the reservoir prior to 1996 had resulted in a significant drop in pressure (around $4000 \mathrm{psi}$ ), and therefore coupled geomechanical effects were expected to accompany re-pressurisation. These might influence reservoir performance and operational activities.

Over 80 wells have been drilled at ReB and these provided the major dataset for reservoir characterisation. Seismic data was available but is unfortunately of poor quality. Outcrop analogue data was also available and proved of significant benefit for upscaling from the well observations. From these sources, detailed fracture characterisation was used to build local-scale fracture models of key areas in the field, which were used to underpin reservoir simulations. In parallel, detailed observations of reservoir stress were made and used to help evaluate coupled geomechanical effects. The work has shown that reservoir characterisation utilising the techniques described here can significantly reduce development risk and can be applied in similar contexts.

\section{RESERVOIR GEOLOGY}

The reservoir sequence is $550 \mathrm{~m}$ thick and dominated by fluvio-deltaic and estuarine sandstones of Cambrian and possibly early Ordovician age. The bulk of the sequence was deposited in fluvial to tidally influenced channel systems during marine transgression. Matrix properties are variable but define a general trend for improving permeability, but declining porosity, upwards through the sequence and as the sands become more compositionally mature.

Structurally, Rhourde El Baguel is located in a complex anticlinal trap with about $1.4 \mathrm{~km}$ of relief which sits at a restraining bend on one of the constituent faults of the Amguid-Hassi Toureg Ridge, a regional-scale structure at the NW edge of the Ghadames Basin. The structure developed mainly during mid-Cretaceous transpression, however there may also have been further growth during Alpine convergence in the Tertiary. The reservoir rocks are also affected by fracturing related to regional epeirogenic events, some of which pre-date trap formation. In general, the most important fracturing events are thought to range from Hercynian to Austrian in age.

\section{FRACTURE CHARACTERISATION AND MODEL DEVELOPMENT}

The work identified four main categories of fracture i) early formed granulation seams; ii) faults exhibiting extensional or strike-slip displacement, with a range of faultrock products; iii) regional 'background' structures comprising stylolites and opening-mode joints; and iv) fracture swarms which 
probably represent progressive shearing of the background joint system during strike-slip (transpressive) phases of deformation..

Image logs from 24 wells were used to identify fracture distributions, orientations and types across the field. Significant overlap between core and imagery was available in 2 wells and enabled calibration of the imagery with core observations. The subset of open fractures was identified primarily by low amplitude and long transit time responses on ultrasonic images and by conductive responses on microresistivity images. Processed Stoneley wave information was also incorporated, as was dynamic data showing fluid influx (eg from PLT's). Discrete inflows were often spatially associated with fault zones, large open fractures and fracture swarms, features which are inferred to have large lateral extent and/or high probabilities of intersecting adjacent structures. Notably however, flow in many cases was not associated with the biggest fractures but rather with small critically oriented fractures that are inferred to connect into larger structures in their close proximity (e.g. small fractures in the damage zones of either major faults or fracture swarms).

Fracture models were based upon integration of fracture characterisation results with dynamic reservoir data (PLT, interference tests, tracers, etc). Wellbore fracture observations were supplemented with outcrop analogue observations from the Hoggar uplift, which provided very useful comparison of fracture and fault zone properties, patterns and densities, including qualitative input to the models.

The fracture system was modelled as nested or domino-style fault systems in which coplanar, steeply dipping and regularly spaced fracture swarms are nested between bounding shear surfaces. The bounding shear surfaces are fracture swarms or strike slip fault zones of larger thickness, higher fracture intensity and larger displacement than the fracture swarms contained between them. Fracture connectivity is a key aspect of such models and is high both between the components of individual fracture swarms and between fracture swarms and their bounding faults.

Dynamic reservoir data was used to calibrate and reduce uncertainties in the static models.

\section{RESERVOIR STRESS}

A stress model establishing the magnitudes and orientations of the in-situ stress axes was required for three purposes: i) to help predict the behaviour of faults and fractures during depletion and repressurisation of the reservoir; ii) to check whether high shear stress areas correlate to high production; iii) to provide input data for assessments of safe operational pressures (eg for stimulation planning and wellbore stability). The results of the in-situ stress work were used to underpin full-field geomechanical modelling.

Stress axis orientations were derived from rigorous examination of ultrasonic image logs from 29 wells (over 10km of data) for breakout and induced axial fracturing. Wellbore shape analysis from acoustic caliper data was also used to identify examples of fracture slip at the wellbore wall. From this analysis a field wide map of maximum horizontal compressive stress directions $\left(\sigma_{\mathrm{hmax}}\right)$ was produced. Stress magnitudes were derived from integration of density logs, analysis of fracture closure / re-opening pressures and leak-off tests, induced fracturing records, breakout width, and modelling of strike-slip or transpressive shear limits to the least stress. Rock strength data and formation pressures were also incorporated in the calculation of magnitudes, leading to the conclusion that ReB is hosted in a very strong rock capable of supporting high stress anisotropy. This implies that shearing of 'critically oriented' fractures with resulting enhancement of fracture permeability is possible. The stress magnitude study also indicated that the stress regime in the reservoir had changed markedly as a result of depletion.

\section{ACKNOWLEDGEMENTS}

Acknowledgements to BP / Sonarco and Sonatrach for permission to publish; also to Tom Patton (BP), Andy Farmer (Consultant to GeoScience), Tony Batchelor and Peter Ledingham (GeoScience Limited) for permission to use results from their work on this field. 